\title{
Present Challenges in Catalytic Emission Control for Internal Combustion Engines
}

\author{
Dmitry E. Doronkin 1,2,*(D) and Maria Casapu ${ }^{1, *}$ \\ 1 Institute for Chemical Technology and Polymer Chemistry (ITCP), Karlsruhe Institute of Technology (KIT), \\ Engesserstraße 20, 76131 Karlsruhe, Germany \\ 2 Institute of Catalysis Research and Technology (IKFT), Karlsruhe Institute of Technology (KIT), \\ Hermann-von-Helmholtz-Platz 1, 76344 Eggenstein-Leopoldshafen, Germany \\ * Correspondence: dmitry.doronkin@kit.edu (D.E.D.); maria.casapu@kit.edu (M.C.)
}

check for updates

Citation: Doronkin, D.E.; Casapu, M. Present Challenges in Catalytic Emission Control for Internal Combustion Engines. Catalysts 2021, 11, 1019. https://doi.org/10.3390/ catal11091019

Received: 19 August 2021

Accepted: 20 August 2021

Published: 24 August 2021

Publisher's Note: MDPI stays neutral with regard to jurisdictional claims in published maps and institutional affiliations.

Copyright: (c) 2021 by the authors. Licensee MDPI, Basel, Switzerland. This article is an open access article distributed under the terms and conditions of the Creative Commons Attribution (CC BY) license (https:// creativecommons.org/licenses/by/ $4.0 /)$.
Keywords: emission control; exhaust gas aftertreatment; three-way catalysts; diesel oxidation catalysts; selective catalytic reduction; hydrocarbon traps; particulate filters; thermal management strategies

Mobility in the modern world relies on heterogeneous catalysis. Catalysis is not only the cornerstone of the production of both fossil and sustainable fuels, but also makes possible the removal of harmful components from engine exhaust. Despite the ongoing electrification trend seen especially in the passenger car segment, internal combustion engines will be used in the years to come in hybrid powertrains, heavy-duty and off-road markets, and shipping, etc. Therefore, the catalytic aftertreatment systems will continue to be developed in order to improve conversion efficiency, stability, and to reduce the amount of required precious metals.

Diesel oxidation catalysts (DOC) and three-way catalysts (TWC) are indispensable components of any modern exhaust gas aftertreatment system. They comprise a major fraction of the worldwide demand for precious metals and, consequently, are foremost contributors to the high costs of the aftertreatment system. Improvement in the activity and stability of noble metal sites is required for driving the costs down while fulfilling stringent environmental regulations. Hence, it is equally important to precisely identify active species as well as to understand their structural dynamics and aging phenomena. This includes the complex interactions within bimetallic noble metal particles and with the carrier material. To understand processes occurring during catalyst operation and ageing, and to develop representative rapid testing protocols, Giuliano et al. evaluated the activity, surface properties, morphology and noble metal dispersion of a commercial PdRh TWC after real driving and laboratory simulated ageing [1]. Schütz et al., in turn, systematically demonstrated the influence of hydrothermal aging conditions on the morphology and chemical state of the active metals, and their activity in $\mathrm{NO}$ and $\mathrm{CO}$ oxidation for model Pt $/ \mathrm{Al}_{2} \mathrm{O}_{3}, \mathrm{Pd} / \mathrm{Al}_{2} \mathrm{O}_{3}$ and Pt-Pd $/ \mathrm{Al}_{2} \mathrm{O}_{3}$ DOCs [2]. Dolcet et al. investigated dynamics and structure-activity correlations of highly dispersed Pt single sites and clusters supported on ceria during $\mathrm{CO}$ oxidation [3]. Understanding structural peculiarities and deactivation phenomena enables options to regenerate aged catalysts. Such possibility for in situ regeneration of deactivated Rh-based TWCs by applying rapid engine braking was demonstrated by Alikin et al. [4].

Selective catalytic reduction $\left(\mathrm{NH}_{3}-\mathrm{SCR}\right)$ is the most widely used approach to remove $\mathrm{NO}_{x}$ from exhaust of lean-burn engines. Also in this case, deriving structure-activity relationships is currently regarded as a main path to obtain more efficient and durable catalysts at lower costs. In this respect, Shen and Hess propose a new high surface area mesoporous $\mathrm{VO}_{\mathrm{x}} / \mathrm{TiO}_{2} /$ SBA-15 catalyst containing highly dispersed $\mathrm{VO}_{\mathrm{x}}$ oligomeric species and showing a wider temperature window for operation compared with other catalysts with similar 
composition [5]. Another approach to improve the low-temperature performance of SCR catalysts is to locate them closer to the engine, before DOC and turbocharger, which results in exposure to higher pressure but also to unburnt hydrocarbons. The impact of such conditions on the performance of $\mathrm{Cu}$ - and Fe-zeolites was systematically studied by Zengel et al. [6]. Water is a major component in the exhaust gas heavily influencing all reactions in the aftertreatment system. Using temperature programmed desorption studies Villamaina et al. demonstrate and quantify the competition between water and ammonia-the primary $\mathrm{NO}_{\mathrm{x}}$ reducing agent-for adsorption on the active sites in state-of-the-art $\mathrm{Cu}$ - $\mathrm{CHA}$ zeolites used for $\mathrm{NH}_{3}$-SCR [7].

Despite contemporary aftertreatment systems being very efficient in dealing with emissions from combustion engines working in cruise mode, a slip of toxic emissions occurs during the cold start, before the catalysts reach the optimal working temperature. An efficient strategy to meet the stricter emission control regulations is to adsorb the pollutants (hydrocarbons, $\mathrm{NO}_{\mathrm{x}}$ ) on the so-called traps, and later desorb and convert them at higher temperature. Modified zeolites have been demonstrated as efficient hydrocarbon traps. The hydrocarbon retention efficiency of different zeolite frameworks (CHA, MFI, BEA) modified with La was investigated in detail using temperature programmed studies and DRIFTS by Jonsson et al. [8]. Different performance trends were identified by Toops et al. [9] for the same zeolite types when modified with Pd and Ag during hydrocarbon and $\mathrm{NO}_{\mathrm{x}}$ storage. In addition to the composition of the trapping material, the composition of the gaseous feed seem to affect the hydrocarbon storage at low temperatures. In this regard, pronounced effects of water and $\mathrm{CO}$ on the performance of Pd/BEA hydrocarbon traps were further reported by Zelinsky and Epling [10].

Better catalyst materials can only improve the overall aftertreatment efficiency when developed in tandem with accurate sensing and engine control systems. An additional challenge is currently represented by the extreme conditions encountered during engine operation, such as the cold start and start-stop operation mode (especially important for hybrid vehicles [11]), combined with very cold or very hot environments [12]. To illustrate but also to overcome this difficulty, the performance of modern gasoline particulate filters (GPF) under extreme conditions was evaluated by Giechaskiel et al. [12], and several solutions for improved thermal management were modelled by Souliotis et al. [11].

Summing up, this issue illustrates the broadness of the exhaust gas aftertreatment catalysis field and comprises the most important research topics related to the emissions of internal combustion engines, including $\mathrm{CO}$ and $\mathrm{HCs}$ oxidation, $\mathrm{HCs}$ and $\mathrm{NO}_{\mathrm{x}}$ traps, $\mathrm{NO}_{x}$ reduction, and particulate matter filtration. On another axis, the whole life-cycle of an emission control catalyst is covered, starting from synthesis, operation to catalyst deactivation and regeneration. Furthermore, we are especially happy to see the equally important experimental and modelling studies reported in this issue. We would like to thank all authors for sharing their valuable work and the reviewers for careful reading and useful recommendations, as well as employees of the Catalysts Editorial Office (Caroline Zhan, Szabolcs Kohr and others) for their support in preparing this Special Issue.

Author Contributions: The contributions of D.E.D. and M.C. are equal. All authors have read and agreed to the published version of the manuscript.

Funding: This research received no external funding.

Conflicts of Interest: The authors declare no conflict of interest.

\section{References}

1. Giuliano, M.; Valsania, M.C.; Ticali, P.; Sartoretti, E.; Morandi, S.; Bensaid, S.; Ricchiardi, G.; Sgroi, M. Characterization of the Evolution of Noble Metal Particles in a Commercial Three-Way Catalyst: Correlation between Real and Simulated Ageing. Catalysts 2021, 11, 247. [CrossRef]

2. Schütz, J.; Störmer, H.; Lott, P.; Deutschmann, O. Effects of Hydrothermal Aging on CO and NO Oxidation Activity over Monometallic and Bimetallic Pt-Pd Catalysts. Catalysts 2021, 11, 300. [CrossRef] 
3. Dolcet, P.; Maurer, F.; Casapu, M.; Grunwaldt, J.-D. Insights into the Structural Dynamics of Pt/CeO ${ }_{2}$ Single-Site Catalysts during CO Oxidation. Catalysts 2021, 11, 617. [CrossRef]

4. Alikin, E.A.; Denisov, S.P.; Bubnov, K.V.; Vedyagin, A.A. Self-Regeneration Effect of Three-Way Catalysts during Thermal Aging Procedure. Catalysts 2020, 10, 1257. [CrossRef]

5. Shen, J.; Hess, C. High Surface Area $\mathrm{VO}_{\mathrm{x}} / \mathrm{TiO}_{2} / \mathrm{SBA}-15$ Model Catalysts for Ammonia SCR Prepared by Atomic Layer Deposition. Catalysts 2020, 10, 1386. [CrossRef]

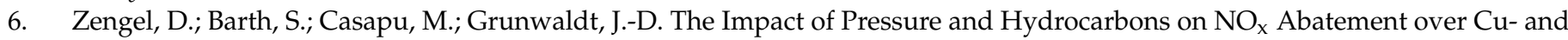
Fe-Zeolites at Pre-Turbocharger Position. Catalysts 2021, 11, 336. [CrossRef]

7. Villamaina, R.; Gramigni, F.; Iacobone, U.; Liu, S.; Nova, I.; Tronconi, E.; Ruggeri, M.P.; Collier, J.; York, A.P.E.; Thompsett, D. The $\mathrm{H}_{2} \mathrm{O}$ Effect on $\mathrm{Cu}$ Speciation in Cu-CHA-Catalysts for $\mathrm{NH}_{3}-\mathrm{SCR}$ Probed by $\mathrm{NH}_{3}$ Titration. Catalysts 2021, 11, 759. [CrossRef]

8. Jonsson, R.; Ho, P.H.; Wang, A.; Skoglundh, M.; Olsson, L. The Impact of Lanthanum and Zeolite Structure on Hydrocarbon Storage. Catalysts 2021, 11, 635. [CrossRef]

9. Toops, T.J.; Binder, A.J.; Kunal, P.; Kyriakidou, E.A.; Choi, J.-S. Analysis of Ion-Exchanged ZSM-5, BEA, and SSZ-13 Zeolite Trapping Materials under Realistic Exhaust Conditions. Catalysts 2021, 11, 449. [CrossRef]

10. Zelinsky, R.; Epling, W.S. Effects of $\mathrm{CO}$ and $\mathrm{H}_{2} \mathrm{O}$ Co-Feed on the Adsorption and Oxidation Properties of a Pd/BEA Hydrocarbon Trap. Catalysts 2021, 11, 348. [CrossRef]

11. Souliotis, T.; Koltsakis, G.; Samaras, Z. Catalyst Modeling Challenges for Electrified Powertrains. Catalysts 2021, 11, 539. [CrossRef]

12. Giechaskiel, B.; Valverde, V.; Kontses, A.; Melas, A.; Martini, G.; Balazs, J.; Andersson, J.; Samaras, Z.; Dilara, P. Particle Number Emissions of a Euro 6d-Temp Gasoline Vehicle under Extreme Temperatures and Driving Conditions. Catalysts 2021, 11, 607. 